GRUBBA, Leilane Serratine; AQUINO, Sérgio Fernandes de. Direitos humanos: o problema do contexto. Revista Eletrônica Direito e Política, Programa de Pós-Graduação Stricto Sensu em Ciência Jurídica da UNIVALI, Itajaí, v.10, n.3, $2^{\circ}$ quadrimestre de 2015. Disponível em: www.univali.br/direitoepolitica - ISSN 1980-7791

\title{
DIREITOS HUMANOS: O PROBLEMA DO CONTEXTO
}

\author{
HUMAN RIGHTS: THE PROBLEM OF CONTEXT
}

\author{
Leilane Serratine Grubba ${ }^{1}$ \\ Sérgio Fernandes de Aquino
}

RESUMO: Introdução; 1 Todo O Texto Tem O Seu Contexto; 2 A Teoria Crítica da Reinvenção dos Direitos Humanos; Considerações Finais; Referências das Fontes Citadas.

\section{RESUMO}

O artigo tem por objeto os direitos humanos e objetiva analisar os direitos humanos de maneira contextual e complexa. Por meio do método dedutivo, o artigo problematiza a concepção hegemônica, ocidental e contemporânea dos direitos humanos e analisa a teoria da reinvenção dos direitos humanos, criada pelo jusfilósofo espanhol Joaquín Herrera Flores, por meio da qual a dignidade humana deve ser analisada contextualmente e materialmente. Os direitos, para a teoria da reinvenção, não possuem uma delimitação conceitual pronta, mas são sempre considerados os anseios concretos das pessoas pelos bens materiais e imateriais que perfazem uma vida digna. Por fim, o artigo compreendeu que o ser humano não tem necessidade de direitos em si considerados, normativamente, mas que necessita, acima de tudo, é de dignidade: de uma vida digna na qual possa acender a satisfação dos bens materiais e imateriais, bem como lutar pela satisfação de seus desejos e necessidades.

\footnotetext{
1 A autora é Doutora em Direito (UFSC) e Mestre em Direito (UFSC), Professora do Programa de Pós-Graduação Scrito Sensu da Faculdade Meridional (IMED), Professora do Programa de PósGraduação Lato Sensu da Faculdade Meridional (IMED), Professora do Programa de PósGraduação Lato Sensu da Universidade Nove de Julho (UNINOVE), Professora do Curso de Direito da Faculdade Meridional (IMED), Professora do Curso de Direito da Faculdade CESUSC, Professora da Escola Superior do Ministério Público de Santa Catarina, bem como pesquisadora da Fundação Meridional. E-mail: Isgrubba@hotmail.com

2 Doutor em Ciência Jurídica pela Universidade do Vale do Itajaí - UNIVALI. Professor do Programa de Pós-Graduação Scrito Sensu da Faculdade Meridional (IMED) e Professor do Curso de Direito da Faculdade Meridional (IMED), bem como pesquisador da Fundação Meridional. E-mail: sergiorfaquino@gmail.com
} 
GRUBBA, Leilane Serratine; AQUINO, Sérgio Fernandes de. Direitos humanos: o problema do contexto. Revista Eletrônica Direito e Política, Programa de Pós-Graduação Stricto Sensu em Ciência Jurídica da UNIVALI, Itajaí, v.10, n.3, $2^{\circ}$ quadrimestre de 2015. Disponível em: www.univali.br/direitoepolitica - ISSN 1980-7791

PALAVRAS-CHAVE: Direitos Humanos; Teoria da Reinvenção; Dignidade Humana; Complexidade; Herrera Flores.

\section{ABSTRACT}

This article aims the human rights and objectively analyzed the complexity and the context of the human rights. Through deductive method, the article questions the hegemonic, western and contemporary conception of human rights and analyzes the theory of reinvention of human rights, established by the Spanish philosopher Joaquín Herrera Flores, where by human dignity must be examined contextually and materially. The rights to the theory of reinvention, do not have a ready conceptual delimitation, but are always considered the concrete aspirations of the people for material and immaterial goods that make up a life of dignity. Finally, Article understood that the human being has no need of rights itself considered normative, but it needs, above all, is dignity: a dignified life in which to light the satisfaction of material and immaterial goods, as well how to fight for the satisfaction of their wants and needs.

KEYWORDS: Human Rights; Theory of Reinvention; Human Dignity; Complexity; HerreraFlores

\section{INTRODUÇÃO}

Os direitos humanos, desde a sua origem e como são concebidos modernamente pela cultura ocidental universalizada, são caracterizados por uma ambiguidade. A esperança em alcançarmos um padrão mínimo jurídico e ético para garantir igualitariamente a dignidade humana, convive, contraditoriamente, com a violação de tais garantias, com a consequente produção genocídios, imperialismo, e ocultamentos. A universalidade desses direitos despreza a práxis da relação humana nos diferentes contextos culturais no globo. O silêncio conta a dignidade parece uníssono.

A positivação de leis de direitos humanos, apesar de importante, não garante, necessariamente, na sua eficácia, pois, conforme os relatórios de desenvolvimento humano das Nações Unidas, as violações aos direitos humanos e à dignidade, etc., ainda em pleno século XXI, atingem milhões de pessoas. 
GRUBBA, Leilane Serratine; AQUINO, Sérgio Fernandes de. Direitos humanos: o problema do contexto. Revista Eletrônica Direito e Política, Programa de Pós-Graduação Stricto Sensu em Ciência Jurídica da UNIVALI, Itajaí, v.10, n.3, 20 quadrimestre de 2015. Disponível em: www.univali.br/direitoepolitica - ISSN 1980-7791

Existem diversas maneiras de exclusão e marginalização de humanos, aos quais são negadas as possibilidades de viver uma vida digna. Não obstante o importante esforço internacional que formulou juridicamente a base mínima de direitos, previstos em textos internacionais, como a Declaração Universal dos Direitos Humanos de 1848, para abranger todas as formas de vida humana, bem como a constitucionalização de direitos fundamentais no âmbito de grande parte dos Estados mundiais, os direitos humanos constituem o principal desafio teórico e prático do século XXI.

Devemos, hoje, recuperar as dualidades teóricas para deixarmos claro que, no marco temporal que vai desde a assinatura da Declaração Universal dos Direitos Humanos até a Iniciativa da Carta Terra, transcorreram mais de cinco décadas nas quais os direitos humanos, paradoxalmente, serviram para promover a luta pela dignidade humana, e para justificar políticas sociais e econômicas neoliberais e materialmente desigualitárias.

Daí porque as reflexões teóricas, filosóficas, éticas e também as práticas sociais para a defesa dos direitos humanos funcionaram, no ocidente, dentro do esquema conceitual e, não por isso, ideológico, estabelecido pelo Preâmbulo e pelo artigo 1.1 da Declaração Universal de 1948, situados no mais puro paradigma jusnaturalista.

Segundo Arendt ${ }^{3}$, a concepção jusnaturalista consubstanciada na Declaração Francesa de 1789 foi incorporada na Declaração Universal dos direitos Humanos de 1948. Para exemplificar a afirmação, vejamos o artigo primeiro preceitua que todos os humanos nascem livres e iguais em dignidade e direitos. Todavia, para Arendt, não nascemos iguais, mas podemos nos tornar iguais (igualmente) enquanto membros de uma coletividade. A igualdade, portanto, é um construído convencional à ação humana, ou seja, um construído histórico.

É necessário pensar se esse marco conceitual pode alavancar ou dificultar as práticas sociais, as novas teorias e similares, que buscam a concretização da

\footnotetext{
${ }^{3}$ ARENDT, Hannah. Crises da república. São Paulo: perspectiva, 1973.
} 
GRUBBA, Leilane Serratine; AQUINO, Sérgio Fernandes de. Direitos humanos: o problema do contexto. Revista Eletrônica Direito e Política, Programa de Pós-Graduação Stricto Sensu em Ciência Jurídica da UNIVALI, Itajaí, v.10, n.3, 20 quadrimestre de 2015. Disponível em: www.univali.br/direitoepolitica - ISSN 1980-7791

dignidade humana no contexto da modernidade pós Guerra Fria - terceira transição do capital -, vinculada intrinsecamente às legitimações economicistas das políticas públicas nacionais e globais ${ }^{4}$.

Primeiramente, conforme salientou Herrera Flores ${ }^{5}$ (2009a, p. 29), o contexto da Guerra Fria, processo de descolonização e política pública interventora no mercado, no qual os direitos humanos passaram a ser formulados juridicamente na contemporaneidade, difere-se do paradigma neoliberal no qual vivemos, tanto em termos sociais, quanto em econômicos e políticos.

Politicamente, a queda do muro de Berlin iniciou o processo de paralisação das medidas estatais interventoras na economia, de modo que o próprio mercado autorregulado - passou a controlar as políticas públicas, por meio de instituições globais, como o Fundo Monetário Internacional (FMI), Banco Mundial (BM) e, sobretudo, a Organização Mundial do Comércio (OMC).

Nesse percurso, os direitos adquiridos passaram a ser percebidos como custos sociais que devem ser suprimidos em virtude da competitividade, assim como foram substituídos pela noção de liberdade como autonomia. A dignidade não é algo viável, nem desejável, porque reivindica esforços econômicos além daqueles previstos pelas fronteiras nacionais.

O contexto da realidade se modificou. Consequentemente, a teoria também deve se modificar, com a finalidade de contextualizar-se em práticas emancipadoras e críticas da deterioração do meio ambiente, das injustiças comerciais, do consumo desigual, das deficiências sociais, da saúde e da convivência, visando transformá-los em prática social mais justa, igualitária e equilibrada.

Nesse sentido, o artigo tem por objeto os direitos humanos e objetiva analisar contextual e complexamente os direitos humanos. Por meio do método dedutivo, o artigo problematiza a concepção hegemônica dos direitos humanos e analisa a

\footnotetext{
4 HERRERA FLORES, Joaquin. Teoria crítica dos direitos humanos: os direitos humanos como produtos culturais. Rio de Janeiro: Lumen Juris, 2009, p. 143.

5 HERRERA FLORES, Joaquín. A reinvenção dos direitos humanos. Florianópolis: Fundação Boiteux, 2009, p. 29.
} 
GRUBBA, Leilane Serratine; AQUINO, Sérgio Fernandes de. Direitos humanos: o problema do contexto. Revista Eletrônica Direito e Política, Programa de Pós-Graduação Stricto Sensu em Ciência Jurídica da UNIVALI, Itajaí, v.10, n.3, 20 quadrimestre de 2015. Disponível em: www.univali.br/direitoepolitica - ISSN 1980-7791

teoria da reinvenção dos direitos humanos, por meio da qual a dignidade humana deve ser analisada contextualmente e materialmente. Os direitos, para a teoria da reinvenção, não possuem uma delimitação conceitual pronta, mas são sempre considerados os anseios concretos das pessoas pelos bens materiais e imateriais que perfazem uma vida digna.

\section{TODO O TEXTO TEM O SEU CONTEXTO}

Mais do que nunca, tornou-se necessário contextualizar os direitos humanos no marco de relações nos quais estamos inseridos. Herrera Flores (2009b, p. 143) nos fala, por exemplo, da aparente dicotomia entre direitos humanos e direitos fundamentais, entre a metáfora das gerações de direitos e a descrição das gerações de problemas/paradoxos entre direitos e deveres humanos.

Esse cenário se manifesta em virtude de nos acostumamos a trabalhar com uma concepção de direitos humanos elaborada nos séculos XVII e XVIII, na qual, primeiramente os direitos naturais passaram a ser vistos como racionais (jusracionalismo), produzidos pela razão humana.

O direito natural é racional, produzido pela razão humana e emanado, em última instância, dos princípios internos do homem. Por conseguinte, são princípios imutáveis e o que muda é a sociedade concreta que incarna progressivamente esses princípios.

Esquecemo-nos que o direito funcionou como uma ideologia no seio da sociedade que se impôs plenamente ao final do século XVIII, precisamente quando a ideologia política foi reproduzida em linguagem jurídica, para exprimir as condições de existência e reivindicações da nova ordem capitalista que se impunha na França, quando a burguesia se transformou na classe dominante. À época do iluminismo, o direito racional cumpriu sua função de ocultação ao esconder a passagem de um determinado tipo de economia e de relações políticas e sociais para outro ${ }^{6}$.

\footnotetext{
${ }^{6}$ MIAILLE, Michel. Uma introdução crítica ao direito. Lisboa: Moraes, 1979, p. 252, 259, 263.
} 
GRUBBA, Leilane Serratine; AQUINO, Sérgio Fernandes de. Direitos humanos: o problema do contexto. Revista Eletrônica Direito e Política, Programa de Pós-Graduação Stricto Sensu em Ciência Jurídica da UNIVALI, Itajaí, v.10, n.3, $2^{\circ}$ quadrimestre de 2015. Disponível em: www.univali.br/direitoepolitica - ISSN 1980-7791

Devemos, portanto, contextualizar a categoria de direitos humanos no marco de sociedade (política, economia, cultura, entre outros) que permitiu a sua criação e o seu surgimento, mas também pensarmos o contexto atual do século XXI.

A superação das dicotomias acima elencadas vincula-se à contextualização dos fenômenos, ou seja, inserir essas dicotomias nas condições da realidade - social, política, econômica e cultural -, na qual o conhecimento e a prática social ocorrem. Somente dessa forma poderemos ampliar o campo semântico do que entendemos por direitos humanos ${ }^{7}$.

Em sentido oposto, para Bobbio ${ }^{8}$, devemos ter a preocupação de desvencilhar teoria e prática, visto que pertencem a esferas distintas que devem ser mantidas distintas, muito embora, paradoxalmente, esse pensador considere que os direitos são um fenômeno de cunho social.

Todavia, se não ampliarmos essa investigação, teremos como consequência, uma separação das condições de produção do conhecimento do contexto que as tornou possível. Ao se separar a justificação e a legitimação de uma teoria de seu contexto, a teoria parece que nasce naturalmente de um processo de reflexão situado à margem das circunstancias reais que são, em última instância, as que condicionam, ainda que não determinem absolutamente, as aproximações intelectuais.

Dito de outro modo: essa visão levaria a crer que o direito foi tirado dos fatos sociais (extraídos dos fenômenos sociais), o que é incorreto, pois o direito é um fato social que mantém relação estreita com todos os outros fenômenos sociais ${ }^{9}$.

Sob idêntico argumento, não basta apenas nos contentarmos com o entendimento de que o direito se vincula à existência da sociedade por ser, por si só, um fato social, pois uma reflexão (ou inflexão) crítica pressupõe identificarmos que o direito influi no desenvolvimento de um modelo específico

\footnotetext{
7 HERRERA FLORES, Joaquin. Teoria crítica dos direitos humanos: os direitos humanos como produtos culturais. p. 143/144.

${ }^{8}$ BOBBIO, Norberto. A era dos direitos. Rio de Janeiro: Elsevier, 2004, p. 62.

${ }^{9}$ MIAILLE, Michel. Uma introdução crítica ao direito. p. 63 e 281.
} 
GRUBBA, Leilane Serratine; AQUINO, Sérgio Fernandes de. Direitos humanos: o problema do contexto. Revista Eletrônica Direito e Política, Programa de Pós-Graduação Stricto Sensu em Ciência Jurídica da UNIVALI, Itajaí, v.10, n.3, $2^{\circ}$ quadrimestre de 2015. Disponível em: www.univali.br/direitoepolitica - ISSN 1980-7791

de sociedade e que esse direito corresponde a essa sociedade ${ }^{10}$. O direito é, antes de tudo, um fenômeno cultural criado por seres e para seres humanos. A sua deificação metafísica estimula muito mais violência e formas de colonização do Outro em detrimento à paz e emancipação.

Se ocultássemos que as teorias do conhecimento decorrem da imanência do mundo, quer detém fundamento na materialidade, ainda que sejam abstrações teóricas dessa realidade, teríamos como consequência que, aparentemente, elas não seriam responsáveis pelos resultados práticos a que deram causa. De fato, conforme o discurso mais atual das Nações Unidas ${ }^{11}$ :

[Existe a] necessidade de assumir o contexto de uma forma séria quando da reflexão sobre as políticas e os programas que têm mais probabilidade de acelerar o desenvolvimento humano [...] O contexto é claramente fundamental. Existe um crescente consenso de que as mesmas políticas podem exercer diferentes efeitos em diferentes contextos. O que funcionou num local pode não funcionar noutro. Por exemplo, tanto a Maurícia como o Haiti são economias insulares que criaram Zonas de Processamento de Exortações; estas foram altamente bem sucedidas na Maurícia, mas fracassaram no Haiti.

Uma teoria tanto é o resultado dos produtos culturais originados no marco da realidade, quanto influi na modificação ou manutenção dessa mesma realidade. Em suma, queremos afirmar que uma teoria social não nasce do vazio, de um monólogo entediante nos domínios do ego, mas na análise que surge do movimento cultural na(s) sociedade(s). Justamente, por esse motivo, é um produto cultural. Mais ainda: após, a sua implementação prática gera também efeitos nessa mesma sociedade, donde a teoria se originou.

\footnotetext{
${ }^{10}$ MIAILLE, Michel. Uma introdução crítica ao direito. p. 63 e 281.

11 NAÇÕES UNIDAS. Relatório de desenvolvimento humano 2010. A verdadeira riqueza das nações: vias para o desenvolvimento humano, p. 107. Disponível em: <http://hdr.undp.org/en/media/HDR_2010_PT_Complete_reprint.pdf>. Acesso em: 30 mar. 2011.
} 
GRUBBA, Leilane Serratine; AQUINO, Sérgio Fernandes de. Direitos humanos: o problema do contexto. Revista Eletrônica Direito e Política, Programa de Pós-Graduação Stricto Sensu em Ciência Jurídica da UNIVALI, Itajaí, v.10, n.3, 20 quadrimestre de 2015. Disponível em: www.univali.br/direitoepolitica - ISSN 1980-7791

Essa consideração foi o pressuposto da grande crítica de Marx $^{12}$ ao idealismo alemão, principalmente de matriz hegeliana e neo-hegeliana, isto é, a visão de um mundo dominado idealmente por ideias abstratas e conceitos, bem como a interpretação do mundo a partir dessas mesmas suposições.

Em sentido oposto, assim como afirmamos que todo o texto tem seu contexto, para Marx, a análise do humano e da sociedade deve se pautar pela vida concreta: pessoas reais e condições materiais de vida.

Por mais que a teorias possam ser consideradas abstrações, são abstrações (reflexos) da materialidade do mundo em sociedade. São abstrações porque se situam no mundo das ideias humanas, mas são imanentes por estarem vinculadas ao social.

O direito é um fato social e, por isso mesmo, é um fato humano. A condição humana é, em primeiro plano, uma questão de vida material (de sobrevivência concreta e corporalmente) e o direito nasce como um regulador da convivência humana. Por conseguinte, os pressupostos do direito só tem razão de ser quando forem contextuais, quando tiverem como parâmetro a vida real material.

Para ser contextualizada, a teoria deve assumir o compromisso com a construção de críticas emancipatórias do real $^{13}$. Em resumo, precisa se preocupar com a função social do conhecimento, devendo ser consciente do contexto no qual e para o qual aponta, sob pena de recair em justificação ideológica do sistema hegemônico e abstrato dos direitos humanos. O conhecimento é um bem social que não pode ser posto à privatização, nem tampouco à valoração utilitarista.

Por função social do conhecimento, entendemos o trabalho de um pensamento comprometido e crítico, que se posiciona contra a banalização das desigualdades e injustiças globais. Um conhecimento que não invisibiliza ou oculta as condições pelas quais emerge, nem tampouco os contextos que pretende transformar. Em

\footnotetext{
12 MARX, Karl. A ideologia alemã. Feuerbach - a oposição entre as concepções materialista e idealista. 3. ed. São Paulo: Martin Claret, 2008.

13 HERRERA FLORES, Joaquin. Teoria crítica dos direitos humanos: os direitos humanos como produtos culturais. p. 144.
} 
GRUBBA, Leilane Serratine; AQUINO, Sérgio Fernandes de. Direitos humanos: o problema do contexto. Revista Eletrônica Direito e Política, Programa de Pós-Graduação Stricto Sensu em Ciência Jurídica da UNIVALI, Itajaí, v.10, n.3, $2^{\circ}$ quadrimestre de 2015. Disponível em: www.univali.br/direitoepolitica - ISSN 1980-7791

suma, trata-se de um conhecimento teórico estreitamente vinculado à prática do mundo concreto, em seus efeitos e causas, bem como em sua razão de existência ${ }^{14}$.

Que se pretende com a função social do conhecimento?

Primeiramente, o conhecimento crítico pressupõe a crítica do próprio conhecimento $^{15}$. No caso dos direitos humanos, trata-se de uma crítica do próprio conhecimento colonialista e imperialista, para que seja adotado um conhecimento democrático-emancipador.

Não é possível que se consagre, a partir do texto normativo dos direitos humanos, um enunciado abstrato, capaz de resolver as mazelas mundiais. A fome, as guerras, o analfabetismo, o exagerado consumismo, precisam de uma resposta a qual seja capaz de modificar a atitudes humanas a partir daquilo que cada contexto cultural enuncia como possibilidade de paz e solidariedade. É o conhecimento cotidiano no qual fomenta esse estar-junto-com-o-Outro-nomundo $^{16}$. Por esse motivo, se insiste, cada vez mais, numa Ecologia dos Saberes ${ }^{17}$ como fundamento de eficácia e eficiência aos direitos humanos.

14 HERRERA FLORES, Joaquin. Teoria crítica dos direitos humanos: os direitos humanos como produtos culturais. p. 146.

15 SOUSA SANTOS, Boaventura de. Para um novo senso comum: a ciência, o direito e a política na transição paradigmática. V1. A crítica da razão indolente: contra o desperdício da experiência. 4. ed. São Paulo: Cortez, 2002, p. 29.

16 "[...] é preciso que haja o Outro para que cada um exista. Truísmo que a biologia, a genética e o social analisam à vontade, e que o senso comum vive, empiricamente, no dia a dia, mas que nossas evidências ideológicas, as da modernidade, se dedicam constantemente a negar. Curiosa persistência de uma ideologia individualista da qual a razão certa e o bom senso reunidos reconhecem a vacuidade! Ser é estar-com, isto é, ajustar-se às leis de harmonia de ordem universal. Não é assim que se pode compreender Anaximandro quando ele fala de diké? Não estreitamento sobre o valor moral e jurídico (o que equivale à mesma coisa) de 'justiça', mas, ao contrário, pela ideia de 'adjunção', isto é, coexistir com a totalidade do mundo, em sua naturalidade ou em sua socialidade". MAFFESOLI, Michel. Homo eroticus: comunhões emocionais. Tradução de Abner Chiquieri. Rio de Janeiro: Forense, 2014, p. 87.

17 "A ecologia dos saberes é um conjunto de epistemologias que partem da possibilidade da diversidade e da globalização contra-hegemônicas e pretendem contribuir para as credibilizar e fortalecer. Assentam em dois pressupostos: 1) não há epistemologias neutras e as que clamam sê-lo são as menos neutras; 2) a reflexão epistemológica deve incidir não nos conhecimento em abstracto, mas nas práticas de conhecimento e seus impactos noutras práticas sociais. Quando falo de ecologia de saberes, entendo-as como ecologia de práticas de saberes". SOUSA SANTOS, 
GRUBBA, Leilane Serratine; AQUINO, Sérgio Fernandes de. Direitos humanos: o problema do contexto. Revista Eletrônica Direito e Política, Programa de Pós-Graduação Stricto Sensu em Ciência Jurídica da UNIVALI, Itajaí, v.10, n.3, $2^{\circ}$ quadrimestre de 2015. Disponível em: www.univali.br/direitoepolitica - ISSN 1980-7791

A partir desse argumento, nos aludimos a um conhecimento que busque a implantação das relações de solidariedade na intersubjetividade humana, nas quais os sujeitos se reconheçam mutuamente, em igualdade substancial, enquanto sujeitos de conhecimento. A solidariedade a que nos referimos, tampouco tem a ver com o assistencialismo caritativo, mas com o compromisso comum de construção de projetos de emancipação social.

É sentido horizontal ${ }^{18}$, próxima da (e sempre animada pela) Fraternidade. Direitos humanos expressam, normativamente, a presença daquela categoria citada, mas jamais essa deve ocorrer pela sua força impositiva ou de uma colonização camaleônica (solidariedade vertical ${ }^{19}$ ). Necessário, portanto, o reconhecimento das pessoas humanas como sujeitos concretos, com carências e necessidade materiais e imateriais, não somente enquanto seres essencialistas e abstratos.

Esse cenário requer a inversão da fórmula cartesiana ${ }^{20}$. Ao invés de dizermos: penso, logo existo, devemos dizer: a existência precede a essência ${ }^{21}$. Em suma,

Boaventura de. A gramática do tempo: para uma nova cultura política. São Paulo: Cortez, 2006, p. 154.

18 Essa "[...] surge do socorro mútuo prestado entre as pessoas, e que se coloca ao lado daquela outra forma de solidariedade, ligada à fraternidade por um vínculo de subsidiariedade, e que chamaremos vertical baseada na intervenção direta do Estado (e dos poderes públicos) em socorro das necessidades. [...] A solidariedade horizontal, por sua vez, diz respeito a um princípio que pode ser deduzido da Constituição, o de um necessário 'socorro mútuo' entre os próprios cidadãos, limitando-se o Estado a oferecer-se como fiador externo. Isso não significa que seja necessário catalogar entre as formas de solidariedade horizontal tão-somente aquelas que as pessoas prestam espontaneamente, sem ser a isso obrigadas ou incentivadas ex lege. Essa forma de socorro, de fato, teria relevância unicamente moral, como exemplo de filantropia, ou meramente factual, mas seria, do ponto de vista jurídico, irrelevante, enquanto não fosse reconhecida como forma tutelada de solidariedade, ou, de qualquer forma, impossibilitada (ao menos por suas próprias forças) de transformar profundamente as relações humanas. Dentre as expressões de solidariedade horizontal poderão, portanto, ser mais uma vez incluídas as tarefas ou deveres de socorro previsto pela legislação, seja esta apenas de caráter premiador (incentivador) ou também obrigatório, a cargo diretamente de sujeitos particulares". PIZOLATTO, Fillipo. A fraternidade no ordenamento jurídico italiano. In: BAGGIO, Antonio Maria (Org.). O princípio esquecido: a fraternidade na reflexão atual da ciência política. Vargem Grande Paulista, (SP): Cidade Nova, 2008, p. 113/114.

19 "[...] A solidariedade vertical se expressa nas formas tradicionais de intervenção e ação de Estado social, ou seja, alude à ação direta dos poderes públicos com a intenção de reduzir as desigualdades sociais e permitir o pleno desenvolvimento da pessoa humana". PIZOLATTO, Fillipo. A fraternidade no ordenamento jurídico italiano. In: BAGGIO, Antonio Maria (Org.). O princípio esquecido: a fraternidade na reflexão atual da ciência política. p. 114.

20 DESCARTES, René. Discurso del método. Buenos Aires: Centro Editor de Cultura, 2006. 
GRUBBA, Leilane Serratine; AQUINO, Sérgio Fernandes de. Direitos humanos: o problema do contexto. Revista Eletrônica Direito e Política, Programa de Pós-Graduação Stricto Sensu em Ciência Jurídica da UNIVALI, Itajaí, v.10, n.3, $2^{\circ}$ quadrimestre de 2015. Disponível em: www.univali.br/direitoepolitica - ISSN 1980-7791

significa que o humano não possui uma essência imutável, mas existe tão somente a partir de suas escolhas e ações concretas no mundo.

O humano não existe somente pelo seu pensar, mas pelo ser agir, que deve buscar satisfazer necessidades materiais e imateriais. Nenhum des-velo acerca de nossa humanidade está no nosso "interior", mas no infinito ${ }^{22}$ desconhecido que habita o Outro. É a partir desse estranho que se apresenta diante do "Eu" que, aos poucos, (re)conhece-se a própria humanidade. Existir é, portanto, coexistir. Esse é o signo primordial dos direitos humanos.

$\mathrm{Na}$ medida em que esses direitos viabilizam a Justiça ${ }^{23}$ em cada lugar do território terrestre deve-se realiza-la a partir das condições sócio-políticashistóricas desses lugares de sentido. A vivência das diferentes adversidades locais e a sua superação evita barbáries globais. É a partir dessa compreensão que se consegue envolver as pessoas para agirem em prol de cenários humanos mais pacíficos a partir dos diferentes contextos locais no mundo.

O triunfo dos direitos humanos - como forma de emancipação civilizatória reside em, habitualmente, identificar tudo o que impede ou negligencia modos das pessoas serem mais livres, justas, dignas, iguais e solidárias e mitigá-las

${ }^{21}$ SARTRE, Jean-Paul. O existencialismo é um humanismo. São Paulo: Abril Cultural, 1978, p. 201.

${ }^{22}$ A ideia do infinito, conforme Lévinas, "[...] não é uma noção que uma subjectividade forje casualmente para reflectir uma entidade que não encontra fora de si nada que a limite, que ultrapassa todo limite e, por isso, infinita. A produção da entidade inifinita não pode separar-se da ideia do infinito, porque é precisamente na desproporção entre a ideia do infinito de que ela é ideia que se produz a ultrapassagem dos limites. A ideia do infinito é o modo de ser - a infinição do infinito. O infinito não existe antes para se revelar depois. A sua infinição produz-se como revelação, como uma colocação em $\mathrm{mim}$ da sua ideia. Produz-se no facto inverossímil em que um ser separado fixado na sua identidade, o Mesmo, o Eu contém, no entantno, em si - o que não pode nem conter, nem receber apenas por força de sua identidade. A subjectividade realiza essas exigências impossíveis; o facto surpreendente de conter mais do que é possível conter". LÉVINAS, Emmanuel. Totalidade e infinito. Tradução de José Pinto Ribeiro. Lisboa: Edições 70, 2000, p. 14.

23 "A partir de condições sócio-históricas a Justiça é significada, ou seja, seu referente de análise são as condições concretas da vida; condições de saúde, educação, trabalho, habitação, segurança, lazer, identidade, participação...[...] A Justiça, em uma dimensão de práxis, guarda relação com as reais condições de existência e estas não constituem apenas situações pontuais, isoladas, mas apresentam íntima relação com a realidade político-econômica macro-estrutural". DIAS, Maria da Graça dos Santos. Justiça: referente ético do direito. In: DIAS, Maria da Graça dos Santos; MELO, Osvaldo Ferreira de; SILVA, Moacyr Motta da (Org.). Política jurídica e pósmodernidade. Florianópolis: Conceito Editorial, 2009, p. 41/42. 
GRUBBA, Leilane Serratine; AQUINO, Sérgio Fernandes de. Direitos humanos: o problema do contexto. Revista Eletrônica Direito e Política, Programa de Pós-Graduação Stricto Sensu em Ciência Jurídica da UNIVALI, Itajaí, v.10, n.3, 20 quadrimestre de 2015. Disponível em: www.univali.br/direitoepolitica - ISSN 1980-7791

para todos terem acesso aos bens e direitos capazes de conduzi-los a outros patamares de uma vida mais qualitativa e de proximidade nas relações humanas transfronteiriças. Precisamos, mais e mais, desenvolver a nossa condição de agente ${ }^{24}$ como forma de des-vendar os mistérios desse signo chamado direitos humanos no decorrer do tempo.

Somente se consideramos que todos os humanos existem a partir de suas ações livres no mundo e que necessitam satisfazer necessidades materiais e imateriais concretas, poderemos construir as bases para chegarmos a uma ideia de ser humano generalizado - a humanidade - e dotado de capacidades abstratas para lutar por sua particular concepção da dignidade humana ${ }^{25}$.

Não apenas pensamos o mundo, mas pensamos e atuamos no mundo: devemos teorizar no e para o mundo no qual vivemos. Vivemos como seres que convivem com outros seres e devemos todos e todas exercer nossa liberdade e criar o mundo, ou seja, pensar e atuar nele a partir da imanência.

A teoria crítica dos direitos humanos percebe sua complexidade no empenho da análise dos fundamentos filosóficos, teóricos, políticos, ideológicos, econômicos e sociais vinculados à posição abstrata e transcendental que vê os direitos humanos como entidades alheias ao mundo real no qual vivem as pessoas de carne e osso, de alegria e sofrimento, que devem satisfazer suas necessidades por bens materiais e imateriais para garantir a possibilidade de viver uma vida digna, e que, em razão disso, não percebem as violações que ocorrem nos contextos concretos.

Criticamente se analisa uma teoria tradicional dos direitos humanos que se apresenta completamente desvinculada dos fatos, como se os fatos fossem

\footnotetext{
24 "Portanto, compreender o papel da condição de agente é essencial para reconhecer os indivíduos como pessoas responsáveis: nós não estamos apenas sãos ou enfermos, mas também agimos ou nos recusamos a agir, e podemos optar por agir de um modo ou de outro". SEN, Amartya. Desenvolvimento como liberdade. Tradução de Laura Teixeira Motta. São Paulo: Companhia das Letras, 2000, p. 221.

25 HERRERA FLORES, Joaquin. Teoria crítica dos direitos humanos: os direitos humanos como produtos culturais. p. 147.
} 
GRUBBA, Leilane Serratine; AQUINO, Sérgio Fernandes de. Direitos humanos: o problema do contexto. Revista Eletrônica Direito e Política, Programa de Pós-Graduação Stricto Sensu em Ciência Jurídica da UNIVALI, Itajaí, v.10, n.3, 20 quadrimestre de 2015. Disponível em: www.univali.br/direitoepolitica - ISSN 1980-7791

entidades autônomas e separadas, na qual a ideia abstrata não se contamina pelo concreto do real.

Consideramos que a liberdade de um começa sempre e quando começa a do outro: a fonte de minha liberdade é a liberdade dos demais. Liberdade denota, sempre, responsabilidade. Trata-se de um valor moral substantivo capaz de dissolver a nossa (gélida) indiferença e permitir agir - e viver - junto com o Outro. Disso se deduz que a tarefa básica de uma teoria comprometida com os direitos humanos é a de criar as condições teóricas e práticas para que possamos afirmar a nossa liberdade como uma atividade criadora que não se limita a dar sua própria lei, mas que se erige em constitutiva de seu objeto: de criação do mundo real. Não existe experiência significadora de ser livre sem a presença da alteridade ${ }^{26}$.

Daí que uma teoria que assuma a função social do conhecimento deve ser sempre o resultado de uma reflexão criativa do mundo na medida em que este exige a liberdade humana ${ }^{27}$.

Teorizar em e para a função social do conhecimento é potenciar encontros dialógicos entre seres humanos e intensidades de capacitação de atitudes e aptidões de empoderamento libertário.

Colocar os direitos humanos em seu devido lugar, no contexto de produto cultural, implica não apenas denunciar as ambiguidades oriundas das teorias tradicionais de direitos humanos, filhas do pensamento individualista que marca a sociedade ocidental moderna e pós-moderna, assim como os essencialismos e naturalismos delas oriundos, mas igualmente a propositura de uma alternativa,

${ }^{26}$ A Alteridade, em Lévinas, se manifesta pelo Rosto alheio. É a experiência de acolhimento, de hospitalidade do infinito além daquilo que é compreensível nos domínios do "Eu". Nenhuma cultura deve aniquilar a outra para dominá-la, pois, segundo o mencionado filósofo, "[...] Só o assassínio aspira à negação total. A negação do trabalho e do uso, tal como a negação da representação, efectuam uma tomada ou compreensão, assentam na afirmação ou visam-na. Matar não é dominar, mas aniquilar, renunciar em absoluto à compreensão. [...] Só posso querer matar um ente absolutamente independente, aquele que ultrapassa infinitamente os meus poderes e que desse modo não se opõe a isso, mas paralisa o próprio poder de poder. Outrem é o único ser que eu posso querer matar". LÉVINAS, Emmanuel. Totalidade e infinito. p. 177.

27 HERRERA FLORES, Joaquin. Teoria crítica dos direitos humanos: os direitos humanos como produtos culturais. p. 149. 
GRUBBA, Leilane Serratine; AQUINO, Sérgio Fernandes de. Direitos humanos: o problema do contexto. Revista Eletrônica Direito e Política, Programa de Pós-Graduação Stricto Sensu em Ciência Jurídica da UNIVALI, Itajaí, v.10, n.3, $2^{\circ}$ quadrimestre de 2015. Disponível em: www.univali.br/direitoepolitica - ISSN 1980-7791

uma nova filosofia-prática que não seja nem etnocêntrica, nem tampouco eurocêntrica.

Em resumo, uma filosofia da imanência na qual as ideias e os fatos estão em constante encontro e troca de energia, preocupada com o real da vida digna do ser humano e com a consolidação da possibilidade de se lutar pela dignidade.

Nesse ponto reside a importância da consideração do Relatório de desenvolvimento humano das Nações Unidas $^{28}$, que salienta a impotência da universalidade teórica e política em garantir a riqueza humana. Segundo essa concepção, para além da universalidade das premissas, é necessária a consideração contextual e imanente das regiões, a partir de princípios de dignidade. Isto é, devemos pensar primeiramente os princípios, visto que considerações gerais universalizadas não garantem que uma política particular seja boa em geral para todas as regiões.

Em segundo lugar, devemos levar os contextos a sério, visto que, em última instância, cada Estado detém suas próprias capacidades e limitações políticas. Enfim, é necessário alterarmos as políticas globais, visto que existem desafios inter-regionais que devem ser considerados, como a questão das regras de comércio, as migrações, entre outros ${ }^{29}$.

Em última instância, o desenvolvimento humano não requer soluções abstratas de caráter universal, pois que as políticas devem estar adequadas ao que se faz estrategicamente apropriado em um determinado local, dependendo do contexto concreto de interação humana ${ }^{30}$.

Cada contexto geográfico é possuidor de uma história, de um determinado tipo de instituições - políticas, sociais e econômicas -, de uma cultura própria, um

\footnotetext{
28 NAÇÕES UNIDAS. Relatório de desenvolvimento humano 2010. A verdadeira riqueza das nações: vias para o desenvolvimento humano, p. 9.

29 NAÇÕES UNIDAS. Relatório de desenvolvimento humano 2010. A verdadeira riqueza das nações: vias para o desenvolvimento humano, p. 9.

30 WALTON, M. Capitalism, the state, and the underlying drivers of humam development. Human development research paper 9. Nova Iorque: PNUD-GRDH, 2010.
} 
GRUBBA, Leilane Serratine; AQUINO, Sérgio Fernandes de. Direitos humanos: o problema do contexto. Revista Eletrônica Direito e Política, Programa de Pós-Graduação Stricto Sensu em Ciência Jurídica da UNIVALI, Itajaí, v.10, n.3, 20 quadrimestre de 2015. Disponível em: www.univali.br/direitoepolitica - ISSN 1980-7791

modo de vida específico. Por mais que no mundo contemporâneo exista uma cada vez maior ligação entre localidades distantes e uma transnacionalização dos costumes, não podemos negar o caráter específico de cada povo que mantém a sua identidade própria.

Além de os contextos concretos afetarem diretamente as formas de instituições que Ihes é apropriada, podemos afirmar que a universalização de um modo particular de concepção desenvolvimentista não é a melhor opção. O imperialismo de um valor específico não necessariamente, ademais, tem o condão de ocasionar os melhores resultados (quando não estiver em conformidade com os modos de existência).

O desenvolvimento da riqueza humana ou, em outras palavras, os direitos humanos (dignidade humana), é relativo ao contexto concreto de interações nos quais cada uma e cada um está situado. Por esse motivo, não é possível admitir a face exclusivamente racionalista-dedutiva dos direitos humanos sem que haja, minimamente, uma aproximação sensível diante do excluído, do esquecido, daquele que passa fome, daquele que não possui assegurados direitos e deveres capazes de oportunizar uma vida digna ${ }^{31}$.

\section{A TEORIA CRÍtICA DA REINVENÇÃo dOS DIREITOS HUMANOS}

A teoria crítica dos direitos humanos, nomeada de teoria da (re)invenção dos Direitos Humanos, surgiu como o resultado de um trabalho coletivo realizado na Universidade Pablo de Olavide, em Sevilha, no Programa Oficial de pósgraduação em Direitos Humanos e Desenvolvimento.

\footnotetext{
31 "Com a articulação entre seres humanos, ações, meios e mediações, há que se prestar atenção quando se reificam as produções humanas sobre os próprios seres humanos ou quando são realmente seres humanos o referente de qualquer emancipação e libertação. A partir do direito pode-se e deve-se lutar contra a expressão da subintegração ou subvaloração das pessoas (por exemplo, em matéria de subcidadania ou de migração em situações precárias). Como juristas, devemos saber para que e para quem se interpreta e são utilizados os sistemas jurídicos e de que norma protege ou enfrenta as desigualdades". RUBIO, David Sanchéz. Encantos e desencantos dos direitos humanos: de emacipações, libertações e dominações. Tradução de Ivone Fernandes Morcilho Lixa e Helena Henkin. Porto Alegre: Livraria do Advogado, 2014, p. 37.
} 
GRUBBA, Leilane Serratine; AQUINO, Sérgio Fernandes de. Direitos humanos: o problema do contexto. Revista Eletrônica Direito e Política, Programa de Pós-Graduação Stricto Sensu em Ciência Jurídica da UNIVALI, Itajaí, v.10, n.3, 20 quadrimestre de 2015. Disponível em: www.univali.br/direitoepolitica - ISSN 1980-7791

A concepção de crítica a que nos referimos quando falamos de uma teoria crítica dos direitos humanos é aquela que afirma uma ontologia dos direitos humanos de carga materialista. Isso quer dizer que o valor dos direitos humanos não tem correspondência com os valores em si considerados, mas com os modos de existência humana: imanente, relacional e dialógica, que possibilitam o empoderamento humano para a transformação da realidade ${ }^{32}$.

Essa teoria nasceu dos pensamentos e das ações de pessoas que necessitavam encontrar uma base teórica realista e crítica que apoiasse as diversas manifestações humanas, fossem elas sociais, jurídicas, pedagógicas, culturais, etc., no intuito da construção de um mundo mais justo, igualitário e libertário, no qual a base material da dignidade humana fosse o desenvolvimento instituinte de pessoas, povos e de diferentes culturas.

Desejo esse de construção de um mundo mais humano, que fez com que surgisse e se desenvolvesse o Instituto de Direitos Humanos, Interculturalidade e Desenvolvimento (IDHID), por meio de um esforço coletivo sob a direção do professor e filósofo Joaquín Herrera Flores, que foi quem propriamente construiu a teoria da reinvenção.

Como foi salientado na nota da equipe de tradução do livro Teoria crítica dos direitos humanos, as bases sobre as quais a teoria crítica dos direitos humanos se fundamenta se confundem com os fundamentos de existência do próprio Instituto. Em resumo, acima de tudo, ambos buscam permitir a conscientização e o fortalecimento "[...] de nossas potencialidades, a fim de afastar de uma vez por todas a distância que separa a sofisticação normativa dos direitos humanos da dura realidade que insiste em negá- $\operatorname{los}^{33 \prime \prime}$.

\footnotetext{
32 HERRERA FLORES, Joaquin. Teoria crítica dos direitos humanos: os direitos humanos como produtos culturais. p. 186.

33 HERRERA FLORES, Joaquin. Teoria crítica dos direitos humanos: os direitos humanos como produtos culturais. $p$. XI.
} 
GRUBBA, Leilane Serratine; AQUINO, Sérgio Fernandes de. Direitos humanos: o problema do contexto. Revista Eletrônica Direito e Política, Programa de Pós-Graduação Stricto Sensu em Ciência Jurídica da UNIVALI, Itajaí, v.10, n.3, $2^{\circ}$ quadrimestre de 2015. Disponível em: www.univali.br/direitoepolitica - ISSN 1980-7791

Vivemos em um mundo aberto e plural $^{34}$, que está sempre em constante movimento e reconstrução. Justamente nessa ordem contemporânea, provisória e transitória do século XXI, na qual nada é ontologicamente, mas pode vir-a-ser algo diverso, que Herrera Flores percebeu os Direitos Humanos como o principal desafio teórico e prático a ser enfrentado.

Esse pensador mergulhou, então, reflexiva e inflexivamente, na inquietação de entender o que são os direitos humanos, sua necessidade e sua finalidade, no intuito de propor uma teoria crítica e realista, que os compreendesse em sua complexidade e natureza imperfeita, impura e híbrida.

Mais do que isso, buscou filosófica e politicamente as bases para compreender, de maneira crítica, a desigual distribuição hierárquica dos direitos humanos e da satisfação material de bens aptos a promover uma vida digna para todos e todas. Em sentido oposto a ver os direitos humanos como uma hierarquia essencial e estática de valores com a aparência de imutabilidade e naturalidade, percebeu-os como a própria vida e a luta cotidiana por dignidade.

Se os direitos humanos têm algum significado de preservação de uma convivência (global) mais pacífica é porque o seu lugar de produção, interpretação e aplicação é ser humano nas relações silenciosas de uma galeria subterrânea em constante efervescência denominada cotidiano. Esses direitos se destinam aos seres humanos e são produzidos, interpretados e aplicados por seres humanos.

A deificação dos direitos humanos pela sua natureza metafísica se opõe, radicalmente, à fragilidade, provisoriedade, finitude e precariedade de ser

\footnotetext{
34 "No que diz respeito a uma escala mundial, temos, no contexto da globalização, uma multiculturalidade muito clara. É óbvio e claro que existem diferentes tipos de sociedades multiculturais. É também um fato da factualidade da vida ou existência de uma pluralidade de culturas no mundo e na nossa própria área geográfica. Isto tem consequências negativas (problemas e conflitos de identidade e de coexistência com base na distinção nós/eles ou outros), mas também positivas. E é neste espaço que a cultura jurídica tem que saber se mover. O fato multicultural deve tomar isso como desafio intercultural, ou seja, como tarefa ou programa, como exigência legal que flui a partir da realidade de nossa situação histórica e se concentra numa humanidade que deve caminhar junto para conquistar e reconhecer os direitos plenamente humanos e para todos, sem exceção". RUBIO, David Sanchéz. Encantos e desencantos dos direitos humanos: de emacipações, libertações e dominações. p. 44.
} 
GRUBBA, Leilane Serratine; AQUINO, Sérgio Fernandes de. Direitos humanos: o problema do contexto. Revista Eletrônica Direito e Política, Programa de Pós-Graduação Stricto Sensu em Ciência Jurídica da UNIVALI, Itajaí, v.10, n.3, $2^{\circ}$ quadrimestre de 2015. Disponível em: www.univali.br/direitoepolitica - ISSN 1980-7791

humano junto com o Outro no mundo. As adversidades diárias precisam (fortemente) nos sensibilizar a fim de se constituir cenários mais inclusivos, pois, ao agir em favor do Outro como absolutamente Outro, é que a vida digna multidimensional se torna de "carne e osso" em todo o território do globo.

Por conseguinte, os direitos humanos passaram a compreender um duplo âmbito. Em primeiro lugar, um âmbito da necessidade humana (a satisfação das necessidades). Sequencial, embora não subordinadamente, um âmbito de liberdade, isto é, a liberdade individual de pensar e agir, mas também a liberdade social de todos e todas empreenderem um posicionamento enquanto sujeitos políticos. Na medida em que todos possuem (iguais) oportunidades para se ter uma vida mais qualitativa, percebe-se uma ampla distribuição da liberdade.

Reinventar teorias, renovar o conhecimento é uma tarefa coletiva. Por mais que seja frequente, no âmbito de criação de ensaios filosóficos, a utilização do pronome nós e da linguagem na primeira pessoa do plural, seja em função de um sentido retórico, seja pela própria consciência da tarefa filosófica como uma empreitada coletiva, que não se reduz a um eu solitário; para Herrera Flores (1989) e todos os demais membros da Escola de Budapeste, o significado do termo é mais forte.

Dizer nós pensamos implica reconhecer que todos os argumentos, fundamentações epistemológicas e ideias têm em sua base um marco teórico coerente e preciso. Tal como todo o real, é um marco repleto de fissuras, sempre aberto ao novo, à reconstrução e à reinvenção.

Ainda que exista certa divergência de posicionamento, esses autores compartilham um contexto cultural, político e social, que torna impossível a desvinculação de suas ideias. Além disso, tampouco podemos separar a filogênese e ontogênese do movimento em seu conjunto.

Em volta da concepção de um nós foi criada, por conseguinte, uma atmosfera de comunicação sem dominação: uma comunicação horizontal, na qual as ideias já 
GRUBBA, Leilane Serratine; AQUINO, Sérgio Fernandes de. Direitos humanos: o problema do contexto. Revista Eletrônica Direito e Política, Programa de Pós-Graduação Stricto Sensu em Ciência Jurídica da UNIVALI, Itajaí, v.10, n.3, $2^{\circ}$ quadrimestre de 2015. Disponível em: www.univali.br/direitoepolitica - ISSN 1980-7791

não mais eram propriedade de um eu separado, mas constituíam-se num patrimônio comum ${ }^{35}$.

Nesse sentido, os direitos humanos passaram a ser compreendidos como processos que possibilitam a abertura e a consolidação de espaços de luta pela dignidade humana, sempre em sua natureza híbrida e impura. A indignação, nesse momento, se torna vetor de materialização para uma Justiça criativa e não-violenta a qual acolhe o Outro na sua diferença e produz condições para tornar a sua vida mais digna. Por esse motivo, as palavras de Hessel $^{36}$ precisam $^{2}$ ser relembradas:

Eu desejo a todos, a cada um de vocês, que tenham seu motivo de indignação. Isto é precioso. Quando alguma coisa nos indigna, como fiquei indignado com o nazismo, nos transformamos em militantes; fortes e engajados, nos unimos à corrente da história,e a grande corrente da história prossegue graças a cada um de nós. Essa corrente vai em direção de mais justiça, de mais liberdade, mas não da liberdade descontrolada da raposa no galinheiro. [...]. Se você encontrar alguém que não é beneficiado por eles, compadeça-se, ajude-o a conquistá-los.

Nessa linha de pensamento, os direitos humanos foram definidos de maneira inconclusiva. Não existe, por certo, uma delimitação absoluta de seu desenho final, visto que o ser humano não tem necessidade de direitos em si considerados, normativamente. O que o ser humano necessita, acima de tudo, é de dignidade: de uma vida digna na qual possa acender à satisfação dos bens materiais e imateriais, bem como lutar pela satisfação de seus desejos e necessidades.

Percebe-se que esses direitos, no ir e vir dialogal entre as culturas, identificam novas oportunidades de torna a vida sempre mais digna e reivindicam uma resposta, uma atitude de indignação ${ }^{37}$ contra as barbáries humanas.

35 HERRERA FLORES, Joaquin. Teoria crítica dos direitos humanos: os direitos humanos como produtos culturais. p. 22/23.

36 HESSEL, Stéphane. Indignai-vos!. Tradução de Marli Peres. São Paulo: Leya, 2011, p. 16.

37 "É atuando no mundo que nos fazemos. Por isso mesmo é na inserção no mundo e não na adaptação a ele que nos tornamos seres históricos e éticos, capazes de optar, de decidir, de 
GRUBBA, Leilane Serratine; AQUINO, Sérgio Fernandes de. Direitos humanos: o problema do contexto. Revista Eletrônica Direito e Política, Programa de Pós-Graduação Stricto Sensu em Ciência Jurídica da UNIVALI, Itajaí, v.10, n.3, $2^{\circ}$ quadrimestre de 2015. Disponível em: www.univali.br/direitoepolitica - ISSN 1980-7791

Historicamente, surgem novas necessidades as quais ampliam a chance de esclarecemos como podemos agir para mitigar as misérias e desigualdades as quais insistem em se perpetuar como "modo de vida". O desafio (semiológico) dos direitos humanos é reconhecer como cada lugar, cada cultura, contribui, por meio de sua diferença, na superação das violências (físicas, simbólicas, institucionais, psicológicas) que impedem essa proximidade com o estanho no qual surge diante do "Eu".

A partir dessa concepção, a noção dos direitos humanos tomou a forma, nas mãos de Herrera Flores, de um diamante ético e multifacetado, no qual os direitos foram revisitados como um marco pedagógico e de ação.

Para tanto, a grande busca é a da criação dialógica de um universalismo a que se quer chegar, ou seja, a posteriori, pluralista, repleto de contrastes e entrecruzamentos, constitutivamente antagônico ao universalismo que se apresenta como um ponto de partida homogeneizador de pessoas, culturas e diferentes formas de manutenção e reprodução da vida.

Existe, portanto, uma ética do eu-outro, perante a qual todos e todas são merecedores de igual consideração e respeito, dotados da necessidade de desenvolvimento das potencialidades humanas, em ações emancipatórias e capacidades criativas de transformar a realidade.

Nesse sentido, o Relatório de Desenvolvimento Humano das Nações Unidas, desde o ano de 1990, já havia se posicionado. Existe uma nova abordagem acerca do desenvolvimento, baseada na ideia de criação de um ambiente que habilite o desfrute de vidas longas, saudáveis e criativas. Daí porque, para o Relatório, em primeiro lugar, a noção de desenvolvimento pouco tem a ver com o âmbito econômico da vida humana. Refere-se, em sua essência, ao desenvolvimento da riqueza humana.

romper." FREIRE, Paulo. Pedagogia da Indignação: cartas pedagógicas e outros escritos. São Paulo: Unesp, 2000, p. 90. 
GRUBBA, Leilane Serratine; AQUINO, Sérgio Fernandes de. Direitos humanos: o problema do contexto. Revista Eletrônica Direito e Política, Programa de Pós-Graduação Stricto Sensu em Ciência Jurídica da UNIVALI, Itajaí, v.10, n.3, 20 quadrimestre de 2015. Disponível em: www.univali.br/direitoepolitica - ISSN 1980-7791

Segundo o RDH2011, das Nações Unidas ${ }^{38}$, o desenvolvimento humano é o "[...] alargamento das liberdades e capacidades que as pessoas possuem para viverem vidas que valorizam e que tem motivos para valorizar". Trata-se de viver uma vida com significado para além da satisfação das necessidades mais básicas.

Não obstante a importância das normas legais, os direitos não se reduzem às normas. No âmbito da teoria da reinvenção dos direitos humanos, tornou-se urgente a reformulação dos limites de direitos humanos impostos ao longo da história pelas propostas do liberalismo político e econômico (individualismo, competitividade e exploração, com legitimação jurídica formalista e abstrata), para que se atenda aos desejos e necessidades humanas, por meio de uma pauta jurídica, ética e social.

Distinguido os sistemas de garantias do que deve ser garantido, o direito deve ser visto apenas como um meio, dentre outros, a garantir o resultado das lutas de interesses sociais. O uso desse direito deve ser impulsionado pelas necessidades das pessoas, para que se caminhe rumo à emancipação dos valores e dos processos de divisão do fazer humano hegemônico, a partir de uma perspectiva contextual, crítica e relacional.

Diante disso, buscamos, em definitivo, compreender o porquê uma determinada forma normativa (jurídica), originada de determinada localidade geográfica e temporalmente situada, se universalizou como se fosse o único modo de compreensão da esfera humana, assim como buscamos compreender as consequências mais aparentes geradas no seio desse processo.

A importância dessa análise, mesmo que breve e restrita a um pequeno número de páginas e a uma discussão limitada, reside justamente no que foi denominado

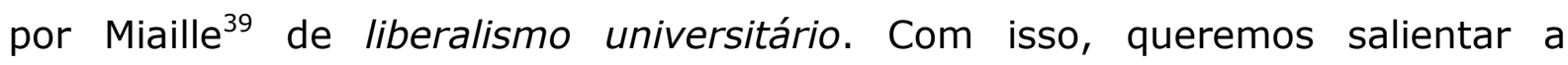
importância da visibilização do que foi ideologicamente ocultado: o liberalismo

\footnotetext{
38 NAÇÕES UNIDAS. Relatório de Desenvolvimento Humano 2011. Sustentabilidade e equidade: um futuro melhor para todos, p. 19/20. Disponível em: <http://hdr.undp.org/en/media/HDR_2011_PT_Complete.pdf>. Acesso em: 18 nov. 2011.

39 MIAILLE, Michel. Uma introdução crítica ao direito. p. 17.
} 
GRUBBA, Leilane Serratine; AQUINO, Sérgio Fernandes de. Direitos humanos: o problema do contexto. Revista Eletrônica Direito e Política, Programa de Pós-Graduação Stricto Sensu em Ciência Jurídica da UNIVALI, Itajaí, v.10, n.3, $2^{\circ}$ quadrimestre de 2015. Disponível em: www.univali.br/direitoepolitica - ISSN 1980-7791

universitário favorece uma situação na qual, se as críticas são possíveis, o espírito crítico se salva em virtude da garantia da liberdade de pensamento.

Todavia, o conjunto do edifício permanece oculto, tal como a base de um iceberg. Em resumo, discutimos diversas correntes filosóficas e políticas, as quais não passam de variantes de uma única melodia, a filosofia idealista e a-histórica dos países ocidentais industrializados ${ }^{40}$.

Devemos mencionar, ademais, a impotência de um trabalho filosófico, como este, frente à práxis, tal como advertiu Herrera Flores ${ }^{41}$. À exceção dos conceitos, a filosofia, por si só, deixa tudo tal como é, em sua própria realidade processual e dinâmica. A filosofia não passa, em última instância, de uma tarefa argumental e conceitual. Daí porque existe a necessidade de buscarmos as bases para compreender essa realidade em seu movimento, ao invés de estudarmos apenas uma fotografia idealmente bela da realidade, isto é, um esquema petrificado do real, por mais que seja coerente e racional.

\section{CONSIDERAÇÕES FINAIS}

O artigo teve por objeto os direitos humanos e objetivou analisar o seu objeto de estudo de maneira contextual e complexa. O artigo problematizou a concepção hegemônica dos direitos humanos e analisou a teoria da reinvenção dos direitos humanos, por meio da qual a dignidade humana deve ser analisada contextualmente e materialmente.

Segundo o que foi abordado, apesar da positivação de direitos humanos e do importante esforço internacional que formulou juridicamente a base mínima dos direitos, são diversas as formas atuais de exclusão de marginalização dos seres humanos, aos quais são negadas as possibilidades de viver uma vida digna.

\footnotetext{
40 MIAILLE, Michel. Uma introdução crítica ao direito. p. 17.

41 HERRERA FLORES, Joaquín. Los derechos humanos desde la escuela de Budapest. Madrid: Tecnos, 1989, p. 147.
} 
GRUBBA, Leilane Serratine; AQUINO, Sérgio Fernandes de. Direitos humanos: o problema do contexto. Revista Eletrônica Direito e Política, Programa de Pós-Graduação Stricto Sensu em Ciência Jurídica da UNIVALI, Itajaí, v.10, n.3, $2^{\circ}$ quadrimestre de 2015. Disponível em: www.univali.br/direitoepolitica - ISSN 1980-7791

As diferentes vozes que vivem a fome, a miséria, a indiferença, o analfabetismo, as desigualdades sociais, econômicas e políticas nunca alcançam os ouvidos daqueles nos quais já se atingiu patamares de vida mais qualitativa. A surdez se torna insuportável, nesse caso, quando se sabe que essa conquista, possivelmente, tenha ocorrido às custas do Outro.

O grande problema verificado é que as formulações teóricas, filosóficas, éticas e também as práticas sociais para a defesa dos direitos humanos funcionaram, no ocidente, dentro do esquema conceitual estabelecido pelo Preâmbulo e pelo artigo 1.1 da Declaração Universal de 1948, situados no mais puro paradigma jusnaturalista.

Qual é esse problema: trata-se de um problema de contexto, que afirma que todos têm direitos essencialmente por ter nascido humanos. Contudo, a realidade normativa nem sempre coincide com a realidade empírica. Quando os direitos humanos não são reconhecidos pela práxis cotidiana em diferentes culturas, esse se torna, tão somente, um nome vazio, reificado, o qual institucionaliza uma mentira exisntecial.

Nesse sentido é que a teoria deve se modificar, para contextualizar-se em práticas emancipadoras e críticas da deterioração do meio ambiente, das injustiças comerciais, do consumo desigual, das deficiências sociais, da saúde e da convivência, visando transformá-los em prática social mais justa, igualitária e equilibrada. Para ser contextualizada, a teoria deve assumir o compromisso com a construção de críticas emancipatórias do real.

Somente no momento que os direitos humanos, como proposta de renovação dos saberes em seus diferentes contextos, se tornam manifestação da vida de todos os dias é que se tornará aquela esperança sensata capaz de tornar a paz mais duradoura nas relações humanas. Esmaece-se, nesse momento, os motivos nos quais intensificam o desespero, bem como a cultura de "colonizar o Outro" sob o pretexto de impor direitos ou outras vias culturais sem qualquer significado para a estabilidade daquele contexto sócio-histórico-político no mundo. 
GRUBBA, Leilane Serratine; AQUINO, Sérgio Fernandes de. Direitos humanos: o problema do contexto. Revista Eletrônica Direito e Política, Programa de Pós-Graduação Stricto Sensu em Ciência Jurídica da UNIVALI, Itajaí, v.10, n.3, 20 quadrimestre de 2015. Disponível em: www.univali.br/direitoepolitica - ISSN 1980-7791

A teoria da reinvenção aparece como uma alternativa contextualizada dos direitos humanos, que buscou filosófica e politicamente as bases para compreender, de maneira crítica, a desigual distribuição hierárquica dos direitos humanos e da satisfação material de bens aptos a promover uma vida digna para todos e todas. Em sentido oposto a ver os direitos humanos como uma hierarquia essencial e estática de valores com a aparência de imutabilidade e naturalidade, percebeu-os como a própria vida e a luta cotidiana por dignidade.

Nesse sentido, os direitos humanos não possuem uma definição conclusiva ou uma delimitação de seu desenho final, mas passaram a ser compreendidos como processos que possibilitam a abertura dialogal entre as diferenças culturais, bem como a consolidação de espaços de luta pela dignidade humana, sempre em sua natureza híbrida e impura. A Justiça disseminada pelos referidos direitos não são considerados, nesse momento, como expressão abstrata e dedutiva em se saber o que é melhor para todos, mas de identificar, em cada localidade, de que forma os direitos humanos se manifestam pela práxis pacífica na vida de todos os dias.

Por fim, se compreendeu que o ser humano não tem necessidade de direitos em si considerados, normativamente, mas que necessita, acima de tudo, é de dignidade: de uma vida digna na qual possa acender a satisfação dos bens materiais e imateriais, bem como lutar pela satisfação de seus desejos e necessidades. Somente no momento que se des-vela esse significado, quando se vive as adversidades de todos no mundo, a ação se destina para aqueles que sofrem, diariamente, com a nossa cegueira e surdez diante das misérias humanas.

\section{REFERÊNCIAS DAS FONTES CITADAS}

ARENDT, Hanna. Crises da república. São Paulo: perspectiva, 1973.

BOBBIO, Norberto. A era dos direitos. Rio de Janeiro: Elsevier, 2004.

DESCARTES, René. Discurso del método. Buenos Aires: Centro Editor de Cultura, 2006.

DIAS, Maria da Graça dos Santos. Justiça: referente ético do direito. In: DIAS, Maria da Graça dos Santos; MELO, Osvaldo Ferreira de; SILVA, Moacyr Motta da 
GRUBBA, Leilane Serratine; AQUINO, Sérgio Fernandes de. Direitos humanos: o problema do contexto. Revista Eletrônica Direito e Política, Programa de Pós-Graduação Stricto Sensu em Ciência Jurídica da UNIVALI, Itajaí, v.10, n.3, $2^{\circ}$ quadrimestre de 2015. Disponível em: www.univali.br/direitoepolitica - ISSN 1980-7791

(Org.). Política jurídica e pós-modernidade. Florianópolis: Conceito Editorial, 2009.

FREIRE, Paulo. Pedagogia da Indignação: cartas pedagógicas e outros escritos. São Paulo: Unesp, 2000.

HERRERA FLORES, Joaquín. A reinvenção dos direitos humanos. Florianópolis: Fundação Boiteux, 2009a.

HERRERA FLORES, Joaquín. Los derechos humanos desde la escuela de Budapest. Madrid: Tecnos, 1989.

HERRERA FLORES, Joaquín. Teoria crítica dos direitos humanos: os direitos humanos como produtos culturais. Rio de Janeiro: Lumen Juris, 2009b.

HESSEL, Stéphane. Indignai-vos!. Tradução de Marli Peres. São Paulo: Leya, 2011.

LÉVINAS, Emmanuel. Totalidade e infinito. Tradução de José Pinto Ribeiro. Lisboa: Edições 70, 2000.

MAFFESOLI, Michel. Homo eroticus: comunhões emocionais. Tradução de Abner Chiquieri. Rio de Janeiro: Forense, 2014.

MARX, Karl. A ideologia alemã. Feuerbach - a oposição entre as concepções materialista e idealista. 3. ed. São Paulo: Martin Claret, 2008.

MIAILLE, Michel. Uma introdução crítica ao direito. Lisboa: Moraes, 1979.

NAÇÕES UNIDAS. Relatório de desenvolvimento humano 1990. Concept and Measurement of human development. Disponível em: < http://hdr.undp.org/en/reports/global/hdr1990/chapters/>. Acesso em: 30 mar. 2011.

NAÇÕES UNIDAS. Relatório de desenvolvimento humano 2010 . A verdadeira riqueza das nações: vias para o desenvolvimento humano. Disponível em: <http://hdr.undp.org/en/media/HDR_2010_PT_Complete_reprint.pdf>. Acesso em: 30 mar. 2011.

NAÇÕES UNIDAS. Relatório de Desenvolvimento Humano 2011. Sustentabilidade e equidade: um futuro melhor para todos. Disponível em: <http://hdr.undp.org/en/media/HDR_2011_PT_Complete.pdf>. Acesso em: 18 nov. 2011.

PIZOLATTO, Fillipo. A fraternidade no ordenamento jurídico italiano. In: BAGGIO, Antonio Maria (Org.). O princípio esquecido: a fraternidade na reflexão atual da ciência política. Vargem Grande Paulista, (SP): Cidade Nova, 2008.

RUBIO, David Sanchéz. Encantos e desencantos dos direitos humanos: de emacipações, libertações e dominações. Tradução de Ivone Fernandes Morcilho Lixa e Helena Henkin. Porto Alegre: Livraria do Advogado, 2014. 
GRUBBA, Leilane Serratine; AQUINO, Sérgio Fernandes de. Direitos humanos: o problema do contexto. Revista Eletrônica Direito e Política, Programa de Pós-Graduação Stricto Sensu em Ciência Jurídica da UNIVALI, Itajaí, v.10, n.3, 20 quadrimestre de 2015. Disponível em: www.univali.br/direitoepolitica - ISSN 1980-7791

SARTRE, Jean-Paul. O existencialismo é um humanismo. São Paulo: Abril Cultural, 1978.

SARTRE, Jean-Paul. O ser e o nada: ensaio de ontologia fenomenológica. Petrópolis: Vozes, 2001.

SEN, Amartya. Desenvolvimento como liberdade. Tradução de Laura Teixeira Motta. São Paulo: Companhia das Letras, 2000.

SOUSA SANTOS, Boaventura de. A gramática do tempo: para uma nova cultura política. São Paulo: Cortez, 2006.

SOUSA SANTOS, Boaventura de. Para um novo senso comum: a ciência, o direito e a política na transição paradigmática. V1. A crítica da razão indolente: contra o desperdício da experiência. 4. ed. São Paulo: Cortez, 2002. p. 29.

WALTON, M. Capitalism, the state, and the underlying drivers of humam development. Human development research paper 9. Nova Iorque: PNUDGRDH, 2010. 